\title{
Activation and repression of transcription by the gap proteins hunchback and Krüppel in cultured Drosophila cells
}

\author{
Ping Zuo, Dušan Stanojević, John Colgan, Kyuhyung Han, Michael Levine, and James L. Manley \\ Department of Biological Sciences, Columbia University, New York, New York 10027 USA
}

\begin{abstract}
We have studied the ability of the Drosophila gap proteins Krüppel and hunchback to function as transcriptional regulators in cultured cells. Both proteins bind to specific sites in a 100-bp DNA fragment located upstream of the segment polarity gene engrailed, which also contains functional binding sites for a number of homeo box proteins. The hunchback protein is a strikingly concentration-dependent activator of transcription, capable of functioning both by itself and also synergistically with the pair-rule proteins fushi tarazu and paired. In contrast, Krüppel is a transcriptional repressor that can block transcription induced either by hunchback or by several different homeo box proteins. While repression of the homeo box protein activators requires a Krüppel-binding site on the DNA, repression of hunchback can occur efficiently in the absence of a Krüppel-binding site. We discuss the possible molecular mechanisms underlying these activities, as well as the potential significance of these results with respect to segmentation in Drosophila.
\end{abstract}

[Key Words: Drosophila gap proteins; segment polarity gene; pair-rule proteins; homeo box protein]

Received August 20, 1990; revised version accepted November 27, 1990.

The segmentation process in Drosophila is controlled by a set of $\sim 25$ regulatory genes that are active in the early embryo (for review, see Akam 1987; Ingham 1988). Localized expression of the segmentation genes depends on a hierarchy of regulatory interactions (for review, see Scott and O'Farrell 1986). The first step is the establishment of broadly distributed gradients of maternal morphogens during oogenesis. The best understood of these is the homeo box protein bicoid $(b c d)$, which plays a key role in localized expression of the next class of genes in the hierarchy, the gap genes (Frigerio et al. 1986; Frohnhöfer and Nüsslein-Volhard 1986; Driever and NüssleinVolhard 1988a,b). Each gap gene is expressed in one or two broad domains that span several adjacent segment primordia. They influence the segmentation process by regulating the expression of the pair-rule genes, which are each expressed as seven stripes in alternating segment primordia along the length of the embryo (Carroll and Scott 1986; Ingham et al. 1986; Frasch et al. 1987). The pair-rule genes implement segmentation by controlling the expression of the segment polarity genes, which are expressed within specific subsets of cells in all 14 segment primordium (Kornberg et al. 1985; DiNardo and O'Farrell 1987).

A recurring theme of this regulatory hierarchy is the progressive refinement in the patterns of gene expression, whereby a given segmentation gene displays a relatively sharp "on/off" pattern of expression in response to cruder gradients of factors upstream in the hierarchy. This process transduces the broad gradients of maternal morphogens (c.g., bcd) into the precise, single-cell limits of expression seen for the segment polarity genes. Perhaps the most dramatic increase in the complexity of these patterns involves the transition from the broad domains of the gap genes to the periodic expression of the pair-rule genes. A central problem in understanding the molecular basis of segmentation is how relatively few, broadly expressed gap genes are able to specify periodic patterns of stripes. The domains of gap gene expression are now known to result in overlapping concentration gradients of each of the different gap proteins /Gaul and Jäcklc 1989; Stanojevic et al. 1989). Consistent with the view that these expression patterns are functionally significant, genetic studies suggest that both the concentrations and combinations of gap proteins are in some way important for determining the on/off periodicity of pairrule promoters (for review, see Carroll 1990).

The gap genes characterized to date all encode DNAbinding proteins, and the most thoroughly studied contain DNA-binding $\mathrm{Zn}^{2+}$ fingers (Rosenberg et al. 1986; Tautz et al. 1987; Nauber et al. 1988; Redemann et al. 1988). Krüppel (Kr)and hunchback (hb) proteins have both been shown to bind to specific DNA sequences, each recognizing a distinct 10 -bp consensus. Binding sites have been detected upstream of several potential target genes (Pankratz et al. 1989, 1990; Stanojevic et al. 
1989; Treisman and Desplan 1989/, the most striking example being the localization of $>20 \mathrm{hb}$-binding sites in a 1.7-kb DNA segment situated upstream of the pairrule gene even-skipped (eve) (Stanojevic et al. 1989). A number of genetic studies are consistent with the idea that $h b$ can be an activator and $K r$ a repressor of gene expression (Jäckle et al. 1986; Frasch and Levine 1987; Carroll and Vavra 1989; Pankratz et al. 1990). However, it is difficult from genetic studies alone to distinguish between direct and indirect effects, and it has also been suggested that $h b$ can act negatively and $K r$ positively (e.g., Pankratz et al. 1989, 1990; Struhl 1989).

Most of the other segmentation genes that have been cloned and characterized also encode sequence-specific DNA-binding proteins (for review, see Levine and Manley 1990|. Mechanistically, the best understood are the homeo box-containing proteins, including the bcd protein, the pair-rule proteins eve, fushi tarazu (ftz), and paired (prd), and the protein encoded by the segment polarity gene engrailed (en). With the exception of $b c d$ (Driever and Nüsslein-Volhard 1989), all recognize a common 10-bp consensus sequence (Desplan et al. 1988; Hoey and Levine 1988). Furthermore, all five are able to modulate transcription, as demonstrated by transient cotransfection (Jaynes and O'Farrell 1988; Han et al. 1989; Winslow et al. 19891, embryo microinjection (Driever and Nüsslein-Volhard 1989), expression studies in yeast (Fitzpatrick and Ingles 1989; Struhl et al. 1989), and in vitro transcription assays (Biggin and Tijan 1989; Ohkuma et al. 1990). These types of experiments have also provided evidence that the concentration gradient of $b c d$ in the carly embryo is functionally significant, as activation of the $h b$ promoter by $b c d$ was found to be markedly dependent on the concentration of the activator (Driever et al. 1989; Struhl et al. 1989). Likewise, the notion that combinatorial interactions between different segmentation gene products are important for correct pattern formation was strengthened by the observations that the $f t z$ and prd proteins can function cooperatively to bring about strong synergistic activation of transcription (Han et al. 1989), while eve and en proteins are able to block the activation induced by $\mathrm{ftz}$ and/or prd (Jaynes and O'Farrell 1988; Han et al. 1989).

Here we show that the gap proteins $K r$ and $h b$ function as transcriptional regulators in cultured cells. Unexpectedly, binding sites for both proteins were found in a wellcharacterized DNA segment located upstream of the en gene, which also contains functional binding sites for several of the pair-rule proteins mentioned above. We present evidence that $h b$ can function as an activator of transcription and $K r$ as a repressor. We show further that these two gap proteins can functionally interact, not only with each other but also with several homeo box proteins.

\section{Results}

To determine whether the proteins encoded by the gap genes $K r$ and $h b$ can function as sequence-specific transcription factors, we employed a transient expression as- say similar to that utilized previously by us and others to examine the activities of several Drosophila homeo box proteins (e.g., Jaynes and O'Farrell 1988; Han et al. 1989; Krasnow et al. 1989). Specifically, Schneider line 2 cells were cotransfected with plasmids capable of expressing $K r$ or $h b$ proteins, an appropriate reporter plasmid, and an internal control plasmid (see Materials and methods). Indirect immunofluorescence assays indicated that both proteins were efficiently expressed in transfected cells (results not shown). Reporter plasmids used in this study contained, except where otherwise indicated, the metallothionein "basal" promoter (i.e., TATA box plus transcriptional start site) fused to the Escherichia coli chloramphenicol acetyltransferase (CAT) gene, with DNA fragments containing $\mathrm{Kr}$ - and $h b$-binding sites ligated upstream (e.g., see Fig. 2). In preliminary experiments, we tested fragments from the eve $5^{\prime}$-flanking region shown previously to contain multiple $h b$ - and/or $K r$-binding sites (Stanojevic et al. 1989). Cotransfection with $h b$ and/or $K r$ expression vectors failed to reveal significant effects on promoter activity with these reporter plasmids (results not shown), perhaps reflecting requirements for additional factors. However, we were surprised to observe that a plasmid nominally used as a control, $\mathbf{k}^{\prime}$-TATA-CAT, was, under certain conditions, responsive to both $K r$ and $h b$ (see below).

The $\mathrm{k}^{\prime}$ fragment is a 100-bp DNA segment naturally located $5^{\prime}$ to the en promoter and was shown previously to contain five consensus binding sites for a number of different homeo box proteins (Desplan et al. 1988; Hoey and Levine 19881, all of which can modulate transcription in response to these sequences (Han et al. 1989). To determine whether $K r$ and/or $h b$ proteins might also be able to function by directly binding to sequences within $\mathbf{k}^{\prime}$, we analyzed the ability of $K r$ and $h b$ proteins synthesized in $E$. coli to footprint on the $\mathrm{k}^{\prime}$ fragment. The results, shown in Figure 1A, indicate that both proteins bind specifically to sequences within fragment $\mathbf{k}^{\prime} . h b$ protein protects two regions from DNase I digestion, whereas $K r$ protects one site. Examination of the nucleotide sequences of the protected regions revealed in each case an excellent match to the previously determined consensus for each protein (Stanojevic et al. 1989). These findings are summarized in Figure 1B, which also indicates the previously defined homeo box protein-binding sites. Note the striking overlap of the $K r$ site with the two head-to-head homeo box-binding sites. An additional match $(8 / 10)$ to the $h b$ consensus overlaps the second of the three head-to-tail homeo box sites. However, we have never observed protection of this site, and its significance is unknown.

\section{The hb protein is a transcriptional activator}

To investigate the ability of the $h b$ protein to modulate transcription in response to the en $\mathrm{k}^{\prime}$ fragment, we first asked whether CAT expression from reporter plasmids containing single or multiple copies of either $k^{\prime}$ or smaller subfragments was affected by $h b$ in cotransfection assays. The sequences of the kI and kII subfrag- 
Figure 1. $K r$ and $h b$ proteins bind to specific sites in the $\mathrm{k}^{\prime}$ fragment of the en promoter. $(A)$ Footprint analysis of $h b$ - and $K r$-binding sites in the $\mathrm{k}^{\prime}$ fragment. A 500-bp HindIII-EcoRI fragment containing the $\mathrm{k}^{\prime}$ fragment from $\mathbf{k}^{\prime}$-TATA-CAT was ${ }^{32} \mathrm{P}$-labeled at the HindIII site and incubated with increasing amounts of $K r$ or $h b$ protein extracts. Following DNase digestion, samples were resolved on an $8 \%$ polyacrylamide- $7.5 \mathrm{M}$ urea gel. The samples shown in lanes 3 and 4 contained 50 or $75 \mu \mathrm{g}$, respectively, of $K_{r}$ protein extract. One region was protected from digestion with DNase I /indicated by the solid rectangle, right). The samples in lanes 5-7 contained 25,75 , or $150 \mu \mathrm{g}$, respectively, of $h b$ protein extract. Two regions of protection were observed, hbl and hb2 (open rectangles, right). Lane $2(-)$ displays a control in which DNase I digestion of the HindIII-EcoRI fragment was performed without added protein. Lane 8 (C) shows a control done with $75 \mu \mathrm{g}$ of protein extract from cells containing the $\mathrm{T} 7$ expression vector without $h b$ or $K r$ cDNA inserts. Lane 1 (GA) shows a G + A sequencing reaction of the HindIII-EcoRI DNA fragment. $(B)$ Position of binding sites in the $\mathbf{k}^{\prime}$ fragment. The numbers -949 and -849 indicate the distance (in $b p$ ) of the $k^{\prime}$ fragment from the en transcription start site. The thin arrows indicate the five binding sites for a number of different homeo box proteins. The bold arrows indicate the $h b$-and $K r$-binding sites determined from the DNase I protection analysis shown in Fig. 1A. The match of each site to previously established $h b$ and $K r$ consensus se-

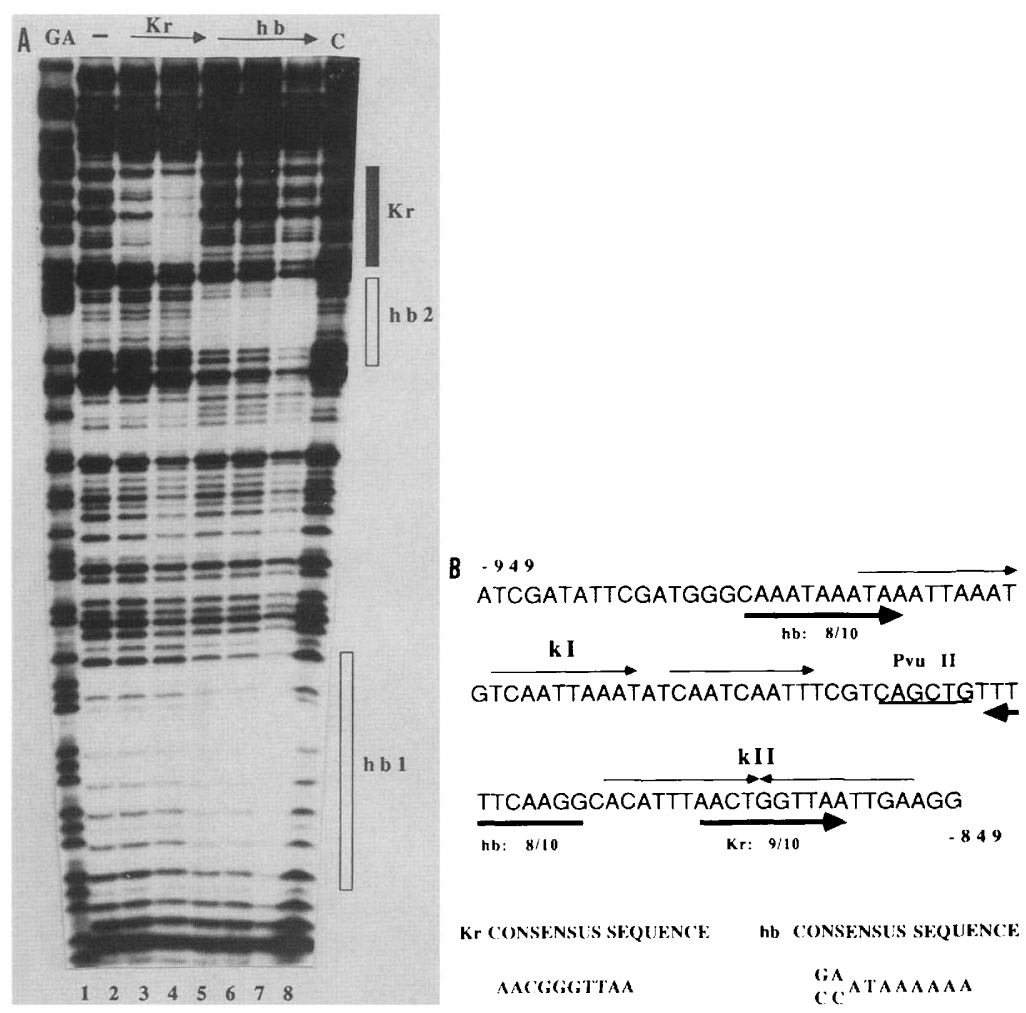
quences (Stanojevic et al. 1989) is indicated, and these sequences are shown at the bottom. A Pvull site that defines the boundary between the $\mathrm{kI}$ and $\mathrm{kII}$ subfragments is indicated.

ments are indicated in Figure 1B. The 63-bp kI fragment contains the three head-to-tail homeo box protein-binding sites and a $h b$ site, while the 37-bp kII fragment contains the second, inverted $h b$ site, the single $K r$ site, and the two head-to-head homeo box protein sites.

Figure 2 displays the relative CAT activities obtained when the indicated reporter plasmids were cotransfected with the actin $5 \mathrm{C}$ promoter-containing expression vector either lacking an insert (Act-PPA) or with $h b$-coding sequences inserted $($ Act- $h b)$. To facilitate comparisons of the effects of $h b$ on the different reporter constructs, all values were normalized so that in each case the CAT activities from the cotransfections with Act-PPA were set at 1.0 (see legend to Fig. 2). The results indicate that the $h b$ protein is a sequence-specific activator of transcription, giving rise to a 20 -fold activation with the reporter construct containing a single copy of the kI fragment. However, the behavior of $h b$ was somewhat unusual. Although activation was observed with both the intact $\mathrm{k}^{\prime}$ fragment and the $\mathrm{kI}$ subfragment, increasing the number of either of these fragments resulted in significantly decreased $h b$-dependent promoter activity. This is in contrast to many previous studies showing that multimerization of transcription factor-binding sites, including the homeo box-binding sites in the $\mathrm{k}^{\prime}$ fragment itself, frequently leads to substantial increases in promoter activity (e.g., Herr and Clarke 1986; Zenke et al. 1986; Jaynes and O'Farrell 1988; Han et al. 1989). A decrease in activity has not, to our knowledge, been observed previously. Consistent with the fact that increasing the num- ber of potential binding sites decreased activation by $h b$, the $\mathrm{k}^{\prime}$ fragment, which contains two binding sites, was only half as active as the kI fragment, which contains just one. Indeed, the only detectable effect of the kII subfragment was to reduce activation mediated through $\mathrm{kI}$, as a reporter plasmid containing only the kII fragment (kII-TATA-CAT) was unresponsive to $h b$. Although we do not know why the $h b$-binding site in kII was not functional, it does not appear to reflect the inverted orientation of this site, as reversing the orientation of $\mathbf{k I}$ resulted in only a slight reduction in $h b$-induced activation (cf. 2kI-TATA-CAT and 2kI-TATA-CAT-rr).

One possible explanation of the above results is that increasing the local concentration of the $h b$ protein might by some mechanism result in reduced activity. An implication of such a model is that the activity of $h b$ might also be reduced at higher concentrations of protein. To address this possibility, we performed a doseresponse analysis over a wide range of concentrations of $h b$ expression vector, using a constant amount of kITATA-CAT. The results, shown in Figure 3, reveal a somewhat skewed, bell-shaped activation curve. Significant (fourfold) enhancement of CAT expression was achieved with only $10 \mathrm{ng}$ of Act-hb, and optimal (20fold) activation was observed with $200 \mathrm{ng}$. Above this amount, significant decreases in activation were detected, with CAT activity dropping to only threefold above the base line with $1.5 \mu \mathrm{g}$ of Act- $h b$. That increasing amounts of Act $-h b$ resulted in elevated concentrations of $h b$ protein in the transfected cells was verified 


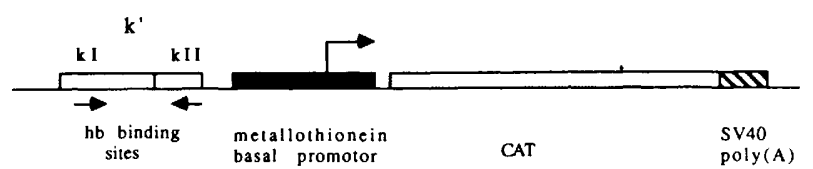

\begin{tabular}{|c|c|c|}
\hline $\begin{array}{lc}\begin{array}{l}\text { Promotor } \\
\text { CAT fusions }\end{array} & \begin{array}{c}\text { Expression } \\
\text { Vectors }\end{array} \\
\end{array}$ & Act-PPA & Act-hb \\
\hline TATA-CAT & 1.0 & 1.2 \\
\hline$k^{\prime}$-TATA-CAT & 1.0 & 9.6 \\
\hline $3 k^{\prime}$-TATA-CAT & 1.0 & 5.3 \\
\hline $5 \mathrm{k}^{\prime}-\mathrm{TATA}-\mathrm{CAT}$ & 1.0 & 3.4 \\
\hline kII-TATA-CAT & 1.0 & 1.1 \\
\hline kI-TATA-CAT & 1.0 & 20 \\
\hline 2kI-TATA-CAT & 1.0 & 12 \\
\hline 2kI-TATA-CAT-Ir & 1.0 & 7.3 \\
\hline 4kl-TATA-CAT & 1.0 & 8.2 \\
\hline
\end{tabular}

Figure 2. $h b$ is a sequence-specific transcription activator. The schematic at the top displays features of the parental reporter plasmid used in these experiments, $\mathrm{k}^{\prime}-\mathrm{TATA}-\mathrm{CAT}$. The arrows denote the $h b$ consensus-binding sites present in the two regions of fragment $\mathrm{k}^{\prime}$, referred to as $\mathrm{kI}$ and $\mathrm{kII}$. The bottom displays the results of cotransfection experiments containing $0.2 \mu \mathrm{g}$ Act-PPA or Act- $h b$ and $5.0 \mu \mathrm{g}$ of the indicated reporter plasmids (see Materials and methods). To compare the effects of $h b$ on the different reporter constructs, all CAT activities were normalized so that in each case the values from the cotransfections with Act-PPA were set at 1.0. The actual basal CAT activities from the different reporter plasmids varied by a factor of 3 or less.

by Western blotting (Fig. 3, insert). This dose-response curve differs from those observed in similar previous experiments with other transcription factors, including our own studies with a number of different homeo box proteins (Han et al. 1989; K. Han and P. Zuo, results not shown). In these cases, activity plateaued and remained essentially constant with as much as $2-5 \mu \mathrm{g}$ of expression vector. Furthermore, the observed inhibition appears to be relatively specific for $h b$-responsive promoters, because expression from several different promoters lacking $h b$-binding sites was not affected by any concentration of Act-hb (results not shown).

hb protein can function cooperatively with pair-rule proteins $\mathrm{ftz}$ and prd

The fact that $h b$ can interact with the en $\mathrm{k}^{\prime}$ fragment to activate transcription raises the question of whether the protein can function synergistically with other proteins that bind this DNA. Specifically, we showed previously that several homeo box proteins that recognize the multiple binding sites within $\mathrm{k}^{\prime}$ can, by themselves, enhance transcription only weakly, but together result in much

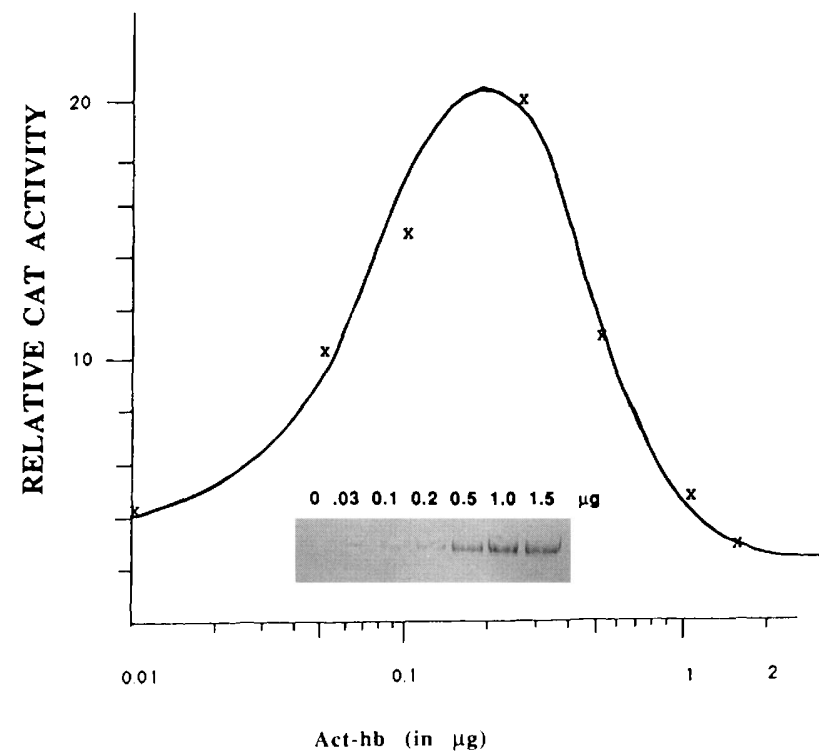

Figure 3. Activation by $h b$ is concentration-dependent. A dose-response analysis was performed over a wide range of concentrations of Act- $h b(0.01-1.5 \mu \mathrm{g})$ with a constant amount of $\mathrm{kl}-\mathrm{TATA}-\mathrm{CAT}(5 \mu \mathrm{g})$. The amount of expression vector in each sample was adjusted to $1.5 \mu \mathrm{g}$ by addition of Act-PPA /see Materials and methods). CAT activities are expressed relative to the activity from kI-TATA-CAT plus $1.5 \mu \mathrm{g}$ of Act-PPA, which was taken as 1.0 . The insert shows the $h b$ protein, detected by Western blotting, in extracts of cells transfected with the indicated amounts of Act- $h b$.

greater synergistic increases in activity (Han et al. 1989). These include the products of the pair-rule genes prd and $f t z$, and the dorsal-ventral gene zerknüllt (zen). To test whether these proteins can function synergistically with $h b$, we performed cotransfection experiments with plasmids expressing each of the proteins, alone or in combinations, along with $\mathrm{k}^{\prime}-\mathrm{TATA}-\mathrm{CAT}$ (Table 1). Although each of these proteins can give rise to significant activation with reporter plasmids containing multiple copies

Table 1. hb functions cooperatively with $\mathrm{ftz}$ or prd but not zen

\begin{tabular}{lc}
\hline Expression vectors & $\mathrm{k}^{\prime}$-TATA-CAT \\
\hline Act-PPA & 1.0 \\
Act- $h b$ & 6.3 \\
Act $-f t z$ & 1.1 \\
Act- $h b+$ Act- $f t z$ & 53 \\
Act-prd & 1.8 \\
Act- $h b+$ Act-prd & 19 \\
Act-zen & 1.6 \\
Act- $h b+$ Act-zen & 8.2
\end{tabular}

Cotransfections were carried out as described in Materials and methods. In each case, $0.5 \mu \mathrm{g}$ of the indicated expression vector was used, together with an appropriate amount of Act-PPA so that all transfections contained $1.0 \mu \mathrm{g}$ of expression vector. The numbers shown are the ratios of the CAT activity obtained from the indicated cotransfection with the CAT activity obtained when $\mathrm{k}^{\prime}$-TATA-CAT was cotransfected with Act-PPA, which was set at 1.0 . 
of $\mathrm{k}^{\prime}$ (Han et al. 1989), they were almost inactive with a single copy of $\mathrm{k}^{\prime}$. However, when cotransfected with Act-hb, synergistic activation of transcription was observed with both $f t z$ and prd. In contrast, the zen protein, although able to function synergistically with $\mathrm{ftz}$ and/or prd, was essentially inactive with $h b$. These results indicate that not only can $h b$ interact synergistically with certain pair-rule proteins but that this synergism is not entirely promiscuous with respect to the nature of the second activator.

The above experiments indicate that $h b$ functions more efficiently with either prd or $f t z$ than it does by itself. An interesting question then becomes whether higher concentrations of $h b$ expression vector, which alone give rise to relatively poor activation, can function effectively with prd or $f t z$. We therefore carried out a dose-response analysis similar to that shown in Figure 3, except that $0.5 \mu \mathrm{g}$ of Act-prd vector was also included in the transfections and $\mathrm{k}^{\prime}$-TATA-CAT was used as the reporter plasmid. The results, shown graphically in Figure 4 , reveal that the concentration of $h b$ that gave optimal activation with prd was significantly higher than when $h b$ was transfected alone. Specifically, $1.2 \mu \mathrm{g}$ of Act $-h b$ gave rise to maximal CAT activity with prd, and activation was only slightly lower with $1.8 \mu \mathrm{g}$ of $h b \mathrm{cx}$ pression vector. This contrasts markedly with the results observed with Act- $h b$ alone, which again showed maximal activation at $200 \mathrm{ng}$. These findings are not likely to reflect differences in $h b$ expression in the cotransfected cells, because expression from an Act-

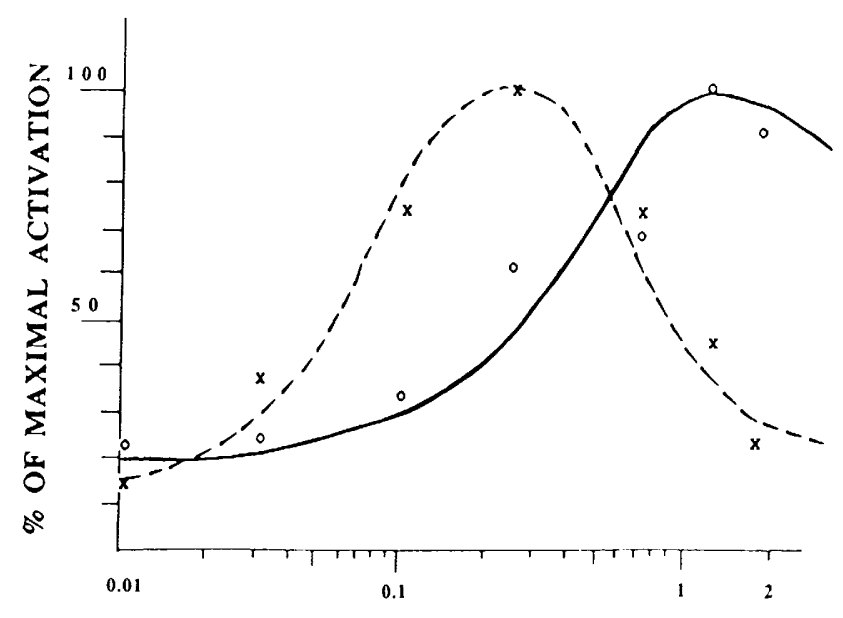

Act-hb (in $\mu$ g) PLC'S

Act-PPA $(\cdot x-\cdot)$ or Act.prd $(-0 \longrightarrow$

Figure 4. High levels of $h b$ function effectively in the presence of a second activator. A dose-response analysis with the indicated amounts of Act $-h b$, similar to that shown in Fig. 3, was performed, except that $0.5 \mu \mathrm{g}$ of Act-prd (solid line) or Act-PPA (dashed line) was included in the transfections, and $\mathrm{k}^{\prime}$-TATA-CAT $(5 \mu \mathrm{g})$ was used as the reporter plasmid. The total amount of expression vector in each sample was adjusted to $2.2 \mu \mathrm{g}$ with Act-PPA. The graph displays the percentage of the maximal activation observed with each concentration of Act $-h b$. Maximal activations were observed with $0.2 \mu \mathrm{g}$ of Act$h b$ plus Act-PPA and $1.2 \mu \mathrm{g}$ when Act-prd was present.
CAT vector was not influenced by cotransfection with Act-prd (results not shown). These results suggest that the high levels of $h b$ protein that alone lead to reduced promoter activation function effectively in the presence of a second activator protein.

\section{$\mathrm{Kr}$ protein is a transcriptional repressor}

To examine the ability of $K r$ to function as a transcriptional regulator, we carried out a series of experiments with an Act $-K r$ expression vector similar to those shown in Figures 2 and 3 with Act-hb. Under no conditions tested was any evidence obtained suggesting that $\mathrm{Kr}$ could activate CAT expression. Rather, reductions of approximately twofold in CAT activity produced from plasmids containing the $\mathrm{k}^{\prime}$ fragment were frequently observed (results not shown). However, because the magnitude of these effects was low and they were not seen reproducibly, we have not pursued further the possibility that $K r$ can function as a direct repressor (Levine and Manley 1989; see Discussion). Instead, we have studied the ability of $K r$ to affect the activation induced by other proteins that interact with the $\mathrm{k}^{\prime}$ fragment.

Table 2 displays the relative CAT activities from cotransfections with several expression vectors encoding homeo box proteins plus or minus a similar amount of the $K r$ expression plasmid, along with $\mathrm{k}^{\prime}-\mathrm{TATA}-\mathrm{CAT}$. In one experiment, we examined the ability of $K r$ to influence the activity of the homeo box protein $z 2$. The $z 2$ gene, which is related to the dorsal-ventral gene zen (Rushlow et al. 1987; Kaufman et al. 1990), encodes a protein that is the strongest $\mathrm{k}^{\prime}$-dependent activator in the cotransfection assays that we have performed (Han et al. 1989). In the experiment shown, $z 2$ induced a 70 -fold activation of $\mathrm{k}^{\prime}$-TATA-CAT in the absence of $K r$ but only a 2.5 -fold activation in its presence. In a second experiment, we asked whether $K r$ could function through the 37-bp kII fragment, which contains the $K r$ binding site centered over two head-to-head homeo box protein sites (see Fig. 1B). Cotransfection of expression vectors encoding $f t z$ and prd, together with kII-TATACAT, resulted in a 15 -fold increase in relative CAT activity (Table 2). When Act-Kr was included in the cotransfection, however, CAT activity was reduced to near basal levels. In contrast, CAT activity was reduced only slightly when a $K r$ expression vector encoding a mutant, DNA binding-defective (results not shown) protein deleted for 183 carboxy-terminal amino acid residues $(K r-2)$, including two of the four putative $\mathrm{Zn}^{2+}$ fingers, was cotransfected with either $z 2$ - or $f t z-$ plus prdencoding plasmids. These results together provide strong support for the notion that the $K r$ protein can function as a transcriptional repressor to block activation induced by several different positive transcription factors.

\section{$\mathrm{Kr}$ specifically blocks activation by hb independent} of $\mathrm{Kr} D N A$-binding sites

The possibility that $K r$ and $h b$ proteins might functionally interact during embryogenesis has been raised by 
Table 2. Kr blocks activation by homeo box proteins

\begin{tabular}{|c|c|c|c|c|c|c|c|c|c|}
\hline \multirow[b]{3}{*}{ Promotor-CAT fusions } & \multicolumn{3}{|c|}{$-K r$} & \multicolumn{3}{|c|}{$+K r$} & \multicolumn{3}{|c|}{$+K r-2$} \\
\hline & \multicolumn{9}{|c|}{ Expression vectors } \\
\hline & Act-PPA & $\mathrm{ftz}+$ prd & $z 2$ & Act-PPA & $\mathrm{ftz}+\mathrm{prd}$ & $z 2$ & Act-PPA & $\mathrm{ftz}+\mathrm{prd}$ & $z 2$ \\
\hline kII-TATA-CAT & 1.0 & 15 & & 0.9 & 1.5 & & 0.9 & 9.5 & \\
\hline $\mathrm{k}^{\prime}$-TATA-CAT & 1.0 & & 70 & 0.8 & & 2.5 & 0.9 & & 62 \\
\hline
\end{tabular}

Cotransfections with the indicated plasmids were performed as described in Materials and methods. Transfections contained $0.5 \mu \mathrm{g}$ each of Act-ftz and Act-prd, $0.2 \mu \mathrm{g}$ of Act $-z 2$, and/or $0.8 \mu \mathrm{g}$ of Act-Kr, as indicated. Act-PPA was added where appropriate so that all transfections contained equivalent amounts of expression vector. Blank spaces indicate combinations that were not tested.

previous studies (e.g., Gaul and Jäckle 1989; Stanojevic et al. 1989; Treisman and Desplan 1989). To address the possibility that one of these two proteins might directly influence the activity of the other, we performed cotransfection experiments in which expression vectors encoding each protein were introduced into Schneider cells, along with one of several different reporter plasmids, and the resulting CAT activities were measured. The results, shown in Figure 5, indicate that $K r$ effectively blocked activation induced by $h b$. Unexpectedly, this was true not only with $\mathrm{k}^{\prime}$-TATA-CAT, which contains binding sites for both proteins (see diagram at bottom of Fig. 5), but also with kI- and 4kI-TATA-CAT, which contain functional $h b$-binding sites but no detectable $K r$ sites, as assayed by both DNase protection (Fig. 1) and gel retention assays (data not shown). These results not only indicate that $K r$ can repress the activity of $h b$ very efficiently but also suggest that this repression can occur in the absence of detectable sequence-specific

\begin{tabular}{|c|c|c|c|c|c|c|c|c|}
\hline $\begin{array}{l}\text { Expression } \\
\text { vectors }\end{array}$ & $\begin{array}{l}\text { Act } \\
\text { PPA }\end{array}$ & $\mathrm{h} \mathrm{b}$ & $\begin{array}{l}\mathrm{hb} \\
+ \\
\mathrm{Kr}\end{array}$ & $\begin{array}{c}\mathrm{hb} \\
+ \\
\mathrm{K} \mathrm{r}-2\end{array}$ & $z 2$ & $\begin{array}{l}2.2 \\
+ \\
\mathrm{Kr}\end{array}$ & $\begin{array}{c}\text { fiz } \\
+ \\
\text { zen }\end{array}$ & $\begin{array}{c}f i z+z e n \\
+ \\
K_{r}\end{array}$ \\
\hline$k^{\prime}$-TATA-CAT & 1.0 & 7.4 & 0.7 & 8.1 & 76 & 2.7 & 25 & 0.9 \\
\hline KI-TATA-CAT & 1.0 & 14 & 1.1 & 13.6 & 140 & 120 & & \\
\hline AKI TATA-CAT & 1.0 & 7.8 & 1.4 & 7.3 & & & 80 & 70 \\
\hline
\end{tabular}

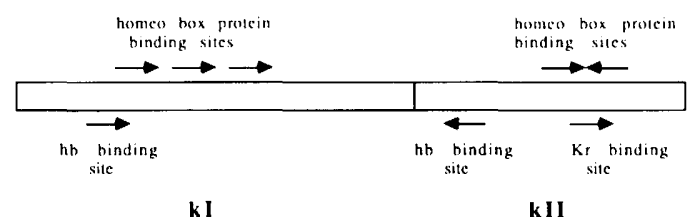

Figure 5. $K r$ specifically blocks activation by $h b$ independent of DNA-binding sites. (Top) The relative CAT activities obtained from cotransfections with the indicated combinations of expression vectors and reporter constructs. Transfections contained $0.2 \mu \mathrm{g}$ of Act-hb or Act-z2, $0.5 \mu \mathrm{g}$ each of Act-ftz and Act-zen, and/or $0.8 \mu \mathrm{g}$ of Act-Kr. Empty squares represent combinations not tested. The schematic at the bottom indicates the homeo box protein $K r$ and $h b$ DNA-binding sites in the kI and kII fragments. Arrows indicate the position and orientation of the sites.
DNA binding by $K r$. The $K r-2$ mutant was unable to repress $h b$-mediated activation from either $\mathrm{k}^{\prime}$ - or kI-containing plasmids (Fig. 5). Thus, the sequences deleted in $K r-2$ appear to be necessary for both binding site-dependent and binding site-independent repression.

To investigate the binding site-independent repression further, we tested whether the ability of $\mathrm{Kr}$ to block the activation induced by several homeo box proteins was dependent on the presence of a $\mathrm{Kr}$ DNA-binding site. We first tested the strong activator protein $z 2$ (Fig. 5). As described above, when the $z 2$ expression vector was cotransfected with $\mathrm{k}^{\prime}$-TATA-CAT, a strong activation was observed, which was almost totally repressed by $K r$. In contrast, when Act-z2 was cotransfected with kITATA-CAT, an even greater increase in CAT expression was observed, but this activation was almost unaffected by coexpression of $K r$. We also tested whether a $K r$ DNAbinding site was required for repression of the synergistic activation induced by two homeo box proteins. Figure 5 shows that with $\mathrm{k}^{\prime}$-TATA-CAT, the combination of the $\mathrm{ftz}$ and zen expression vectors brought about a 25 -fold increase in CAT activity. As with the other activator proteins tested, this increase was effectively repressed by $K r$. However, when the $f t z$ and zen expression vectors were cotransfected with the $4 \mathrm{kI}-\mathrm{TATA}-\mathrm{CAT}$ reporter plasmid, the resulting 80 -fold induction of CAT activity was almost totally resistant to $K r$-mediated repression. These results together indicate that $K r$ can block activation by at least two distinct mechanisms, one requiring a $K r$-binding site and the other independent of such a site.

\section{Repression of z2-dependent activation by $\mathrm{Kr}$ is not} dependent on binding site orientation or position

The above results indicate that $K r$, presumably by binding to its recognition site in the kII fragment, can block activation induced by homeo box proteins interacting with the upstream kI fragment. This observation allowed us to determine whether the spacing or orientation of the $K r$ and homeo box protein-binding sites influences $K r$ function. In one experiment, the orientation of the $\mathrm{k}^{\prime}$ fragment was inverted. This changes the orientation of all the binding sites in $\mathrm{k}^{\prime}$ relative to the basal promoter and also places the $K r$-binding site upstream of the homeo box-binding sites in the kI fragment. In addi- 
tion, another basal promoter, from the heat shock protein 70 gene, was used in this experiment /see Materials and methods), which allowed us to determine whether $\mathrm{Kr}$ repression is influenced by the identity of the basal promoter. As shown in Table 3, when $\mathrm{k}^{\prime}$-hsp-TATA-CAT and $\mathrm{rk}^{\prime}$-hsp-TATA-CAT were cotransfected with Act $z 2$ alone, significant activation, similar to that with $\mathrm{k}^{\prime}$-TATA-CAT, was observed with each. However, when Act- $K r$ was included in the transfections, activation was nearly abolished, indicating that the $K r$ protein can function efficiently in this context of binding sites and basal promoter. To determine whether the spacing between binding sites is important for $K r$ function, kII(90)kI-TATA-CAT was constructed and analyzed (Table 3). In this plasmid the $\mathrm{Kr}$-binding site (kII) is again located upstream of the homeo box sites, but the spacing between them is increased by $90 \mathrm{bp}$ (from 35 to $125 \mathrm{bp}$. CAT expression from this construct was activated by $z 2$ to roughly the same level as with $\mathrm{k}^{\prime}$-TATA-CAT, and this activation was again greatly reduced by $K r$. These findings indicate that the ability of $\mathrm{Kr}$ to block activation induced by the $z 2$ protein is not dependent on the orientation or spacing of the binding sites.

\section{Discussion}

The experiments described above have provided evidence that the products of the gap genes $h b$ and $K r$ can function as transcriptional regulators in Drosophila tissue culture cells. The $h b$ protein is a strongly concentration-dependent activator of expression, functioning relatively poorly at high concentrations or with reporter plasmids containing multiple $h b$-binding sites. $h b$ can also function synergistically with the pair-rule proteins $f t z$ and prd. In contrast, $K r$ is a repressor, capable of blocking activation induced by a number of homeo box proteins, as well as by $h b$. Interestingly a $K r$ DNA-bind-

Table 3. Repression by $\mathrm{Kr}$ is not dependent on binding site position or orientation

\begin{tabular}{|c|c|c|c|}
\hline \multirow[b]{2}{*}{$\begin{array}{l}\text { Promotor- } \\
\text { CAT fusions }\end{array}$} & \multicolumn{3}{|c|}{ Expression vectors } \\
\hline & Act-PPA & Act $-z 2$ & $\begin{array}{c}\text { Act }-z 2 \\
+ \\
\text { Act }-K r\end{array}$ \\
\hline$k^{\prime}$-hsp-TATA-CAT & 1.0 & 45 & 3.2 \\
\hline $\mathbf{r k}^{\prime}-\mathrm{hsp}-\mathrm{TATA}-\mathrm{CAT}$ & 1.0 & 38 & 1.1 \\
\hline $\mathbf{k}^{\prime}-\mathrm{TATA}-\mathrm{CAT}$ & 1.0 & 69 & 2.6 \\
\hline kII $(90) \mathrm{kI}-\mathrm{TATA}-\mathrm{CAT}$ & 1.0 & 95 & 7.9 \\
\hline
\end{tabular}

Cotransfections with the indicated plasmids were performed as described in Materials and methods, except that the amount of the hsp-TATA-CAT reporter plasmids was only $0.1 \mu \mathrm{g}$. This was because the basal level of CAT expression from this promoter was significantly higher than from the TATA-CAT plasmids used elsewhere in this study. The amounts of expression vectors used were the same as in Table 2. CAT activities were normalized so that in each case the values from the cotransfections with Act-PPA were set at 1.0. ing site is apparently not required for repression of $h b$ but is required for repressing the homeo box proteins.

\section{$\mathrm{hb}$ is a concentration-dependent transcriptional activator}

The properties of the $h b$ protein described here are consistent with several previous genetic studies and also provide some insights into the mechanisms by which it might function in the early embryo. The activity of $h b$ has been shown to be required for proper expression of three of the seven eve stripes $(2,3$, and 7; Frasch and Levine 1987; Goto et al. 1989; Harding et al. 1989). Consistent with the findings described here that $h b$ is a transcriptional activator, the cis-acting elements required for expression of these stripes contain multiple $h b$-binding sites, suggesting a direct positive role for $h b$ in eve regulation. Although we have not detected an effect of $h b$ on eve expression in transfection assays, the function of $h b$ in the generation of stripe 3 is nonetheless intriguing in light of the data presented here. The cis-acting sequences required for stripe 3 expression contain $\sim 20 \mathrm{hb}$ binding sites in a 1.7-kb DNA segment (Stanojevic et al. 1989 ) and binding sites for other potential regulators have not been detected (D. Stanojevic and M. Levine, unpubl.). However, the concentration of $h b$ in stripe 3 is low, and it decreases from anterior to posterior. While the posterior boundary of the stripe probably arises simply when a subthreshold level of $h b$ protein is reached, it may be that the anterior boundary is established at the point where $h b$ rises $a b o v e$ a maximum level. The large number of binding sites may be able to respond to low concentrations of $h b$ but would then be repressed at higher levels of protein. This possibility is suggested by the bell-shaped dose-response curve for $h b$ activation, which indicates that high concentrations of $h b$ are inactive, and offers an explanation for the otherwise paradoxical observation that the highest concentrations of $h b$ protein in the early embryo are in cells between those constituting eve stripes 2 and 3 (Stanojevic et al. 1989).

What is the molecular mechanism responsible for the unusual behavior of the $h b$ activator? We suggest two possible models. In one, a limiting factor required to mediate $h b$ function le.g., a "coactivator" (Pugh and Tjian 1990) or "adaptor" (Martin et al. 1990)] is titrated out by high concentrations of $h b$. This would result in "selfsquelching" of $h b$ activity, as has been observed recently with derivatives of the adenovirus Ela protein (Martin et al. 1990; for discussion of squelching, see Ptashne 1988). Note that the hypothetical coactivator is unlikely to be a general transcription factor, because high levels of $h b$ were found not to reduce transcription from a number of different basal promoters. A second model offers an explanation consistent with all the properties of $h b$ described here. Specifically, it suggests that $h b$ activity is controlled by multimerization, with the protein being maximally active as a monomer. That the $h b$-binding site lacks dyad symmetry is consistent with the idea that the protein binds DNA in this form. However, by this model, $h b$ is able to form multimers, either free in solu- 
tion or when bound to DNA, and such forms of the protein are less efficient or nonfunctional as transcriptional activators. In keeping with the notion that $h b$ molecules can interact, some evidence suggests that $h b$ can bind DNA cooperatively (Stanojevic et al. 1989). This model offers an explanation for the lower activity observed with reporter plasmids containing multiple $h b$-binding sites, as this could facilitate formation of $h b$ multimers. In addition, the prd protein, or other proteins with which $h b$ can functionally interact, might interfere with the formation of such inactive complexes by binding to a nearby DNA site, thereby increasing the concentration required of $h b$ required to form multimers on the DNA. Whatever the mechanism, these properties of $h b$ could play an important role in the ability of the protein to bring about the proper spatially and temporally regulated activation of target genes during embryogenesis.

\section{$\mathrm{Kr}$ is a transcriptional repressor}

The data presented here and in a recent study employing mammalian tissue culture cells (Licht et al. 1990) indicate that $K r$ can function as a repressor. This conclusion is consistent with several previous genetic studies. For example, in $\mathrm{Kr}^{-}$embryos the domain of $h b$ expression undergoes a posterior expansion into a region of the embryo that normally expresses high levels of $K r$ protein (Jäckle et al. 1986). Similarly, eve expression stripe 2 also expands posteriorly in $\mathrm{Kr}^{-}$embryos (Frasch and Levine 1987), while the sixth expression stripe of another primary pair-rule gene, hairy $(h)$, expands anteriorly (Ingham et al. 1986). The 5'-flanking regions of both of these genes contain $K r$-binding sites that are within the cisacting elements required for stripe $2(e v e)$ and stripe $6\langle h|$ expression (Stanojevic et al. 1989; Pankratz et al. 1990). It is therefore likely that $K r$ can act as a transcriptional repressor in embryos as it does in cultured cells and that this activity helps define the boundaries of expression of other segmentation genes. As mentioned in the introductory section, there are also genetic experiments suggesting that $K r$ can act positively (and $h b$ negatively). Whether these findings reflect indirect effects (e.g., $\mathrm{Kr}^{-}$ repressing expression of a second repressor) or the ability of these proteins to function as both activators and repressors is not known.

There are several ways by which DNA-binding transcriptional repressors can function to block gene expression (for review, see Levine and Manley 1989), and Kr may exploit at least two of them. In principle, the simplest mechanism is competitive DNA binding, where binding of the repressor prevents or interferes with binding of an activator. It is highly likely that $K r$ can function in this manner. Specifically, given the positioning of binding sites in the kII fragment, where the $K r$ site directly overlaps two head-to-head homeo box sites, it is probable that the repression of prd and ftz is mediated by competitive DNA binding. A second type of repression, termed quenching, occurs when binding of the repressor does not block the binding of an activator but interferes with its function by some other mechanism, for exam- ple, by "masking" its activating domain. It is likely that $K r$ can also function in this manner, as suggested by the following two examples. First, activation induced by $h b$, which occurs through a binding site $\sim 50 \mathrm{bp}$ from the $K r$-binding site in $\mathbf{k}^{\prime}$, is efficiently repressed by $\mathrm{Kr}$. Given the size of the DNA footprints, and the fact that $\mathrm{Kr}$ and $h b$ proteins can simultaneously occupy their respective DNA-binding sites (P. Zuo and D. Stanojević, unpubl.), we consider it unlikely that $K r$ interferes with the binding of $h b$. Furthermore, the fact that a $K r$-binding site is not required for repression of $h b$ is not consistent with DNA-binding competition. Second, $K r$ can repress $z 2$ mediated activition even when the $K r$-binding site is situated $>120 \mathrm{bp}$ upstream of the z2-binding sites [kII(90)kI-TATA-CAT]. Although it has not been shown directly that $\mathrm{Kr}$ and $z 2$ can simultaneously bind to this fragment, it is very likely that they do, given the distance separating the two sites, and a simple binding site competition is again unlikely. Note that these two examples themselves most likely reflect distinct mechanisms, as the latter is dependent on a $K r$ DNA-binding site while the former is not. In addition, because $K r$ can function when its binding site is situated $5^{\prime}$ as well as $3^{\prime}$ of the activators, repression must require more than a simple steric "roadblock" between the activator and the basal transcription machinery. Together, these observations suggest strongly that $K r$ can repress by mechanisms other than binding-site competition and that specific protein-protein interactions are probably involved in this type of repression.

What is the molecular mechanism underlying the ability of $K r$ to quench activation induced by several different positive transcription factors? While it is clear that additional studies will be required to answer this question fully, several points merit discussion. It has recently been shown by Licht et al. (1990) that $K r$ can function as a sequence-specific repressor in mammalian cells and, in the context of fusion proteins with a heterologous DNAbinding domain, that the amino-terminal alanine-rich region of the protein is sufficient to bring about repression. This region may well be necessary for at least some of the effects of $K r$ described here, and we have found that an alanine-rich region in the eve protein plays an important role in its function as a transcriptional repressor (K. Han and J.L. Manley, unpubl.). The data presented here, however, indicate that the carboxy-terminal third of $K r$ is necessary for its function in both DNA-binding site-dependent and -independent repression. In the former case, this is readily explained by the inability of the $\mathrm{Kr}-2$ mutant to bind DNA. However, in the latter case, the deleted sequences must play another role, and a likely possibility is that they are involved in proteinprotein interactions. Indeed, recent studies have implicated sequences in the DNA-binding domains and carboxyl termini of several $\mathrm{Zn}^{2+}$ finger steroid receptors as critical for heterodimer formation [thyroid and retinoid acid receptors (Glass et al. 1989); glucocorticoid receptor and AP-1 (Jonat et al. 1990; Schüle et al. 1990; Yang-Yen et al. 1990]). Although our preliminary experiments have failed to detect such a complex, it is conceivable that $K r$ 
and $h b$ can form a heterodimer that is unable to activate transcription. Alternatively, $K r$ might interact with another protein required for $h b$ function, such as the hypothetical coactivator mentioned above, thereby preventing activation.

\section{$\mathrm{Kr}$ and $\mathrm{hb}$ can functionally interact with homeo box proteins}

The demonstration that $h b$ can function synergistically with the homeo box proteins $f t z$ and prd, while $K r$ can block their activity, raises the possibility that direct competitive and/or cooperative interactions between gap and pair-rule gene products are important for the regulation of gene expression during embryogenesis. In particular, it is conceivable that the segment polarity gene en is regulated by combinatorial interactions between gap and pair-rule products. Genetic studies have provided strong evidence that en expression is controlled by a number of pair-rule genes (DiNardo and O'Farrell 1987; Ingham et al. 1988, and references therein). Because these genes are themselves regulated by the gap genes, it has been assumed that any effects of the gap genes on expression of en would be indirect, mediated through the pair-rule genes. Indeed, there is no evidence that gap genes directly participate in regulation of segment polarity gene expression. However, several observations are consistent with the possible involvement of $h b$ and $K r$ in the regulation of $e n$. First, it is clear that expression of gap genes and segment polarity genes overlap temporally and spatially (e.g., see Ingham 1988), an obvious prerequisite if the gap genes indeed regulate en directly. Second, the earliest patterns of $e n$ expression in the syncytial blastoderm are region specific and not segment specific (Karr et al. 1989), which could reflect the distribution and, hence, the direct involvement, of gap proteins such as $h b$ and $K r$ in the control of en expression. Third, DNA sequence analysis of the $\mathbf{k}^{\prime}$ region of the en promoter from the distantly related species Drosophila virilis (Kassis et al. 1989) reveals that both the $K r$-binding site and the functional (although, intriguingly, not the nonfunctional) $h b$ site are conserved, consistent with the idea that these sites are physiologically significant. Finally, it is noteworthy that pair-rule and gap proteins appear to act in concert to initiate stripes of homeotic gene expression in early embryos (Ingham and Martinez-Arias 1986; Ingham et al. 1986; Harding and Levine 1988). In any event, our results indicate that $K r$ and $h b$ can functionally interact not only with each other but also with several homeo box proteins. Such combinatorial interactions may be important for defining precise patterns of gene expression in the early embryo.

\section{Materials and methods}

\section{Recombinant plasmids}

All expression vectors were derived from a plasmid containing the Drosophila actin 5C promoter and poly(A) site, Act-PPA, which is described in Han et al. (1989). The expression vector Act- $h b$ was constructed from a cDNA clone pEMBL8-hb (pro- vided by G. Struhll. pEMBL8- $h b$ was cleaved with $X b a I$, the ends were filled in, and the 2.4-kb XbaI fragment was inserted into Act-PPA that had been cleaved with BamHI, filled in, and digested with $E c o$ Rv. The 5 '-untranslated leader of Act- $h b$ contains 88 nucleotides from Act $5 \mathrm{C}$ and 13 from $h b$. Act-Kr was constructed from $\mathrm{Kr}$ cDNA clone K405 (provided by G. Struhl), hsp-CAT, and Act-PPA. hsp-CAT, which contains the heat shock protein 70 promoter $-3^{\prime}$ leader fused to the CAT gene, was used as an intermediate to facilitate cloning. Both K405 and hsp-CAT were digested with EcoRI and PstI, and a $3.1-\mathrm{kb}$ fragment from hsp-CAT was ligated with a 2-kb fragment of K405. The resulting plasmid, hsp-Kr was digested with PvuII, and the $1.9-\mathrm{kb}$ fragment was inserted into Act-PPA, which had been cleaved with BamHI and filled in. The resulting Act-Kr plasmid encodes a $K_{r}$ mRNA with a $5^{\prime}$-untranslated leader composed of 88 nucleotides from Act 5C, 104 from hsp70, and 69 from $\mathrm{Kr}$. Act-Kr-2, which encodes a protein deleted for 183 carboxy-terminal amino acid residues, was constructed by digesting Act $-K r$ with $P v u I$, digesting $3^{\prime}$ overhangs with T4 polymerase, and then digesting with NcoI. The resulting 1.4-kb fragment was reinserted into Act-PPA, which had been cleaved with BgIII, filled in, and digested with $N c o l$. The resulting $K r-2$ protein contains 284 amino acids from the $K r$ protein plus 4 extraneous carboxyterminal amino acid residues.

All reporter plasmids were constructed from $k^{\prime}-$ TATA-CAT (described by Han et al. 1989). kI-TATA-CAT was constructed by digesting k'-TATA-CAT with PvuII and HindIII. The 80 -bp fragment containing $\mathrm{kI}$ was inserted into a metallothionein promoter-CAT plasmid (TATA-CAT), which had been digested with Sall, filled in, and cleaved with HindIII. kII-TATA-CAT was constructed by cleaving $\mathrm{k}^{\prime}$-TATA-CAT with EcoRI and partially with PvuII. The 380 -bp fragment containing kII was isolated and inserted into TATA-CAT, which had been digested with SalI, filled in, and partially cleaved with EcoRI. 2kI-TATA-CAT, 2kI-TATA-CAT-rr, and 4kI-TATA-CAT were constructed by digesting PGEM kI / which contains the kI fragment in the SalI site of pGem3) with SalI. The 70-bp kIcontaining fragment was inserted into TATA-CAT, which had been cleaved by SalI. The resulting recombinant plasmids were sequenced to identify the above three plasmids. kII $(90) \mathrm{kI}-$ TATA-CAT was constructed by digesting pGem kII /which contains the kII fragment in the Sall site of pGem3/ with HindIII and PvuII. The resulting 130 -bp fragment containing kII was inserted into kI-TATA-CAT, which had been partially digested with PstI, filled in, and cut with HindIII. In the resulting recombinant plasmid, the kII fragment is located $90 \mathrm{bp}$ upstream from the kI fragment.

\section{DNA transfection and transient expression assays}

Transient cotransfection assays were performed essentially as described previously (Han et al. 1989). Drosophila Schneider L2 cells (Schneider 1972) were grown in M3 medium plus $10 \%$ fetal calf serum, plated at $2 \times 10^{6}$ to $4 \times 10^{6}$ cells $/ 60-\mathrm{mm}$ tissue culture dish 1 day before transfection, and transfected using calcium phosphate coprecipitation. Except where indicated, each transfection contained $0.2-0.8 \mu \mathrm{g}$ of expression vector(s), $5 \mu \mathrm{g}$ of promoter-CAT fusion, and either $2 \mu \mathrm{g}$ of copia-lacZ plasmid or $0.1 \mu \mathrm{g}$ of Act-lacZ plasmid as an internal control. Expression from copia-lac $Z$ was observed to be reduced by a factor of $\sim 3$ by Act- $K r_{\text {; }}$ therefore, Act-lacZ (which was not affected by either Act $-K r$ or any of the other expression vectors) was used in transfections containing Act-Kr. In a given experiment, the amount of actin promoter was kept constant in each sample by the addition of Act-PPA as required. The total amount of DNA was adjusted to $10 \mu \mathrm{g}$ by the addition of pGem3 as carrier. All ex- 
periments were performed in duplicate and repeated at least twice. Transfected cells were incubated at $24^{\circ} \mathrm{C}$ for $48-50 \mathrm{hr}$ before harvesting. Cells were washed twice with PBS, resuspended in $0.1 \mathrm{ml}$ of $0.25 \mathrm{M}$ Tris- $\mathrm{HCl}(\mathrm{pH} 7.8)$, and extracts were prepared by sonicating for $2 \mathrm{~min}$ in an ultrasonic sonifier (Branson), followed by centrifugation for $10 \mathrm{~min}$ in a microfuge. Transfection efficiencies were determined by $\beta$-galactosidase activity assays as described by Han et al. \{1989). Variations between samples within a given experiment were typically less than twofold. CAT assays were also performed as described previously (Han et al. 1989).

\section{DNase I protection assays}

DNA footprinting assays were carried out as described previously (Stanojevic et al. 1989). k'-TATA-CAT was digested with HindIII, end-labeled with $\left[\gamma^{32} \mathrm{P}\right] \mathrm{ATP}$ and polynucleotide kinase, and then cleaved with EcoRI. A labeled fragment of $\sim 500$ bp containing the $\mathrm{k}^{\prime}$ segment and the TATA box region was purified. Bacterial extracts of strains expressing $h b$ or $K r$ were prepared, and increasing amounts of protein were used in DNA binding assays. Binding conditions, DNase digestion, and gel electrophoresis were carried out exactly as described (Stanojevic et al. 1989).

\section{Immunofluorescence and immunoblotting}

Indirect immunofluorescence assays of transfected cells were performed as described (Han et al. 1989). Rabbit anti- $h b$ or anti$K_{r}$ antibodies, raised against SDS gel-purified proteins made in $E$. coli, were used as the first antibody, and rhodamine-conjugated goat anti-rabbit as the second. For immunoblot analysis, nuclear extracts of transfected cells were prepared essentially as described (Dignam et al. 1983), except that the final $\mathrm{NaCl}$ concentration during extraction of the nuclei was $\sim 0.7 \mathrm{M}$. Samples containing $\sim 50 \mu \mathrm{g}$ of total nuclear protein were resolved by electrophoresis through a $12 \%$ SDS-polyacrylamide gel. Proteins were transferred to nitrocellulose essentially as described (Towbin et al. 1979). Rabbit anti- $h b$ antibodies were used as the primary antibody, and these were detected using a Vectastain $\mathrm{ABC}$ kit (Vector Laboratories) as described by the manufacturer.

\section{Acknowledgments}

We thank M. Wang for excellent technical assistance, C. Rushlow for providing the anti-Kr antibodies, and M.A. Scott for preparing the manuscript. This work was supported by National Institutes of Health grant GM 37971.

The publication costs of this article were defrayed in part by payment of page charges. This article must therefore be hereby marked "advertisement" in accordance with 18 USC section 1734 solely to indicate this fact.

\section{References}

Akam, M. 1987. The molecular basis for metameric pattern formation in the Drosophila embryo. Development 101: 122.

Biggin, M.D. and R. Tjian. 1989. A purified Drosophila homeodomain protein represses transcription in vitro. Cell 58: $433-440$.

Carroll, S.B. 1990. Zebra patterns in fly embryos: Activation of stripe or repression of interstripes? Cell 60: 9-16.

Carroll, S.B. and M.P. Scott. 1986. Zygotically active genes that affect the spatial expression of the fushi tarazu segmentation gene during early Drosophila embryogenesis. Cell 45: 47-57.
Carroll, S.B. and S.H. Vavra. 1989. The zygotic control of Drosophila pair-rule gene expression. II. Spatial repression by gap and pair-rule gene products. Development 107: 673-683.

Desplan, C., J. Theis, and P.H. O'Farrell. 1988. The sequence specificity of homeodomain-DNA interactions. Cell 54: 1081-1090.

Dignam, J.D., R.M. Lebovitz, and R.G. Roeder. 1983. Accurate transcription initiation by RNA polymerase II in a soluble extract from mammalian nuclei. Nucleic Acids Res. 11: 1475-1489.

DiNardo, S. and P.H. O'Farrell. 1987. Establishment and refinement of segmental pattern in the Drosophila embryo: Spatial control of engrailed expression by pair-rule genes. Genes 4) Dev. 1: 1212-1225.

Driever, W. and C. Nüsslein-Volhard. 1988a. A gradient of bicoid protein in Drosophila embryos. Cell 54: 83-93.

- $1988 \mathrm{~b}$. The bicoid protein determines position in the Drosophila embryo in a concentration-dependent manner. Cell 54: 95-104.

- 1989. The bicoid protein is a positive regulator of hunchback transcription in the early Drosophila embryo. Nature 337: 138-143.

Driever, W., G. Thoma, and C. Nüsslein-Volhard. 1989. Determination of spatial domains of zygotic gene expression in the Drosophila embryo by the affinity of binding sites for the bicoid morphogen. Nature 340: 363-367.

Fitzpatrick, V.S. and C.J. Ingles. 1989. The Drosophila fushitarazu polypeptide is a DNA binding transcriptional activator in yeast. Nature 337: 666-668.

Frasch, M. and M. Levine. 1987. Complementary patterns of even-skipped and fushi-tarazu expression involve their differential regulation by a common set of segmentation genes in Drosophila. Genes \& Dev. 1: 981-995.

Frasch, M., T. Hoey, C. Rushlow, H. Doyle, and M. Levine. 1987. Characterization and localization of the even-skipped protein of Drosophila. EMBO /. 6: 749-759.

Frigerio, G., M. Burri, D. Bopp, S. Baumgartner, and M. Noll. 1986. Structure of the segmentation gene paired and the Drosophila PRD gene set as part of a gene network. Cell 47: 735-746.

Frohnhöfer, H. and C. Nüsslein-Volhard. 1986. Organization of anterior pattern in the Drosophila embryo by the maternal gene bicoid. Nature 324: 120-125.

Gaul, U. and H. Jäckle. 1989. Analysis of maternal effect mutant combinations elucidates regulation and function of the overlap of hunchback and Krüppel gene expression in the Drosophila blastoderm embryo. Development 107: 651-662.

Glass, C.K., S.M. Lipkin, O.V. Devary, and M.G. Rosenfeld. 1989. Positive and negative regulation of gene transcription by a retinoic acid-thyroid hormone receptor heterodimer. Cell 59: 697-708.

Goto, T., P. MacDonald, and T. Maniatis. 1989. Early and late patterns of even-skipped expression are controlled by distinct regulatory elements that respond to different spatial cues. Cell 57: 413-422.

Han, K., M. Levine, and J.L. Manley. 1989. Synergistic activation and repression of transcription by Drosophila homeo box proteins. Cell 56: 573-583.

Harding, K. and M. Levine. 1988. Gap genes define the limits of Antennapedia and Bithorax gene expression during early development in Drosophila. EMBO I. 7: 205-214.

Harding, K., T. Hoey, R. Warrior, and M. Levine. 1989. Autoregulatory and gap response elements of the even-skipped promoter of Drosophila. EMBO I. 8: 1205-1212.

Herr, W. and J. Clarke. 1986. The SV40 enhancer is composed of multiple functional elements that can compensate for one 
another. Cell 45: 461-470.

Hoey, T. and M. Levine. 1988. Divergent homeo box proteins recognize similar DNA sequences in Drosophila. Nature 332: $858-861$.

Ingham, P.W. 1988. The molecular genetics of embryonic pattern formation in Drosophila. Nature 335: 25-34.

Ingham, P.W. and A. Martinez-Arias. 1986. The correct activation of Antennapedia and bithorax complex genes requires the fushi-tarazu gene. Nature 324: 592-597.

Ingham, P.W., D. Ish-Horowicz, and K. Howard. 1986. Correlative changes in homeotic and segmentation gene expression in Krüppel mutant embryos of Drosophila. EMBO /. 5: 16591665.

Ingham, P.W., N.E. Baker, and A. Martinez-Arias. 1988. Regulation of segment polarity genes in the Drosophila blastoderm by fushi-tarazu and even-skipped. Nature 331: 73-75.

Jäckle, H., D. Tautz, R. Schuh, E. Seifert, and R. Lehmann. 1986. Cross-regulatory interactions among the gap genes of Drosophila. Nature 324: 668-670.

Jaynes, J.B. and P.H. O'Farrell. 1988. Activation and repression of transcription by homeodomain proteins that bind a common site. Nature 336: 744-749.

Jonat, G., H.J. Rahmsdorf, K.-K. Park, and P. Herrlich. 1990. Antitumor promotion and antiinflammation: Down-modulation of AP-1 (Fos/Jun) activity by glucocorticoid hormone. Cell 62: 1189-1204.

Karr, T.L., M.S. Weir, Z. Ali, and T. Kornberg. 1989. Patterns of engrailed protein in early Drosophila embryos. Development 105: 605-612.

Kassis, J.A., C. Desplan, D.K. Wright, and P.H. O'Farrell. 1989. Evolutionary conservation of homeodomain binding sites and other sequences upstream and within the major transcription unit of the Drosophila segmentation gene engrailed. Mol. Cell. Biol. 9: 4304-4311.

Kaufman, T.C., M.A. Seeger, and G. Olsen. 1990. Molecular and genetic organization of the Antennapedia gene complex of Drosophila melanogaster. Adv. Genet. 27: 309-362.

Kornberg, T., I. Siden, P. O'Farrell, and M. Simon. 1985. The engrailed locus of Drosophila in situ localization of transcripts reveals compartment-specific expression. Cell 40: $45-53$.

Krasnow, M.A., E.E. Saffman, K. Kornfeld, and D.S. Hogness. 1989. Transcriptional activation and repression by Ultrabithorax proteins in cultured Drosophila cells. Cell 57: $1031-1043$.

Levine, M. and J.L. Manley. 1989. Transcriptional repression of eukaryotic promoters. Cell 59: 405-408.

- 1991. Transcriptional control of Drosophila embryogenesis. In Molecular aspects of cellular recognition (ed. P. Cohen and G. Foulkes), vol. 6. 447-467.

Licht, J.D., M.J. Grossel, J. Figge, and U.M. Hansen. 1990. Drosophila Krüppel protein is a transcriptional repressor. Nature 346: 76-79.

Martin, K.J., J.W. Lillie, and M.R. Green. 1990. Evidence for interaction of different eukaryotic transcriptional activators with distinct cellular targets. Nature 346: 147-152.

Nauber, U., M. Pankratz, A. Kienlin, E. Seifert, U. Klemm, and H. Jäckle. 1988. Abdominal segmentation in the Drosophila embryo requires a hormone receptor-like protein encoded by the gap gene knirps. Nature 336: 489-492.

Ohkuma, Y., M. Horikoshi, R.G. Roeder, and C. Desplan. 1990. Binding-site dependent direct activation and repression of in vitro transcription by Drosophila homeodomain proteins. Cell 61: 475-484.

Pankratz, M.J., M. Hoch, E. Seifert, and H. Jäckle. 1989. Krüppel requirement for knirps enhancement reflects overlapping gap gene activities in the Drosophila embryo. Nature 341: 337-340.

Pankratz, M.J., E. Seifert, N. Gerwin, B. Billi, U. Nauber, and H. Jäckle. 1990. Gradients of Krüppel and knirps gene products direct pair-rule gene stripe patterning in the posterior region of the Drosophila embryo. Cell 61: 309-317.

Ptashne, M. 1988. How eukaryotic transcriptional activators work. Nature 335: 683-689.

Pugh, B.F. and R. Tiian. 1990. Mechanism of transcriptional activation by SP1: Evidence for coactivators. Cell 61: 11871197.

Redemann, N., U. Gaul, and H. Jäckle. 1988. Disruption of a putative Cys-zinc interaction eliminates the biological activity of the Krüppel finger protein. Nature 332: 90-92.

Rosenberg, U.B., C. Schroder, A. Preiss, A. Kienlin, S. Cote, I. Riede, and H. Jäckle. 1986. Structural homology of the Drosophila Krüppel gene with Xenopus transcription factor IIIa. Nature 319: 336-339.

Rushlow, C., H. Doyle, T. Hoey, and M. Levine. 1987. Molecular characterization of the zerknüllt region of the Antennapedia gene complex in Drosophila. Genes $\Leftrightarrow$ Dev. 1: 12681279.

Schneider, I. 1972. Cell lines derived from late embryonic stages of Drosophila melanogaster. I. Embryol. Exp. Morphol. 27: 353-365.

Schüle, P., P. Rangarajan, S. Kliewer, L.J. Ransone, J. Bolado, N. Yang, I.M. Verma, and R.M. Evans. 1990. Functional antagonism between oncoprotein c-Jun and the glucocorticoid receptor. Cell 62: 1217-1226.

Scott, M.P. and P.H. O'Farrell. 1986. Spatial programming of gene expression in early Drosophila embryogenesis. Annu. Rev. Cell. Biol. 2: 49-80.

Stanojevic, D., T. Hoey, and M. Levine. 1989. Sequence-specific DNA-binding activities of the gap proteins encoded by hunchback and Krüppel in Drosophila. Nature 341: 331335.

Struhl, G. 1989. Differing strategies for organizing anterior and posterior pattern in Drosophila embryos. Nature 338: 741744.

Struhl, G., K. Struhl, and P.M. MacDonald. 1989. The gradient morphogen bicoid is a concentration-dependent transcriptional activator. Cell 57: 1259-1273.

Tautz, D., R. Lehmann, H. Schnurch, R. Schuh, E. Seifert, A. Kienlin, K. Jones, and H. Jäckle. 1987. Finger protein of novel structure encoded by hunchback, a second member of the gap class of Drosophila segmentation genes. Nature 327: 383-389.

Towbin, H., T. Staehelin, and I. Gordon. 1979. Electrophoretic transfer of proteins from polyacrylamide gels to nitrocellulose sheets: Procedures and some applications. Proc. Natl. Acad. Sci. 76: 4350-4354.

Treismann, J. and C. Desplan. 1989. The products of the Drosophila gap genes hunchback and Krüppel bind to the hunchback promoters. Nature 341: 335-337.

Winslow, G.M., S. Hayashi, M. Krasnow, D.S. Hogness, and M.P. Scott. 1989. Transcriptional activation by the Antennapedia and fushi-tarazu proteins in cultured Drosophila cells. Cell 57: 1017-1030.

Yang-Yen, H.-F., J.-C. Chambard, and Y.-L. Sun. 1990. Transcriptional interference between c-Jun and the glucocorticoid receptor: Mutual inhibition of DNA binding due to direct protein-protein interaction. Cell 62: 1205-1215.

Zenke, M., T. Grundstrom, H. Matthes, M. Wintzerith, C. Schatz, A. Wilderman, and P. Chambon. 1986. Multiple sequence motifs are involved in SV40 enhancer function. EMBO I. 5: 387-397. 


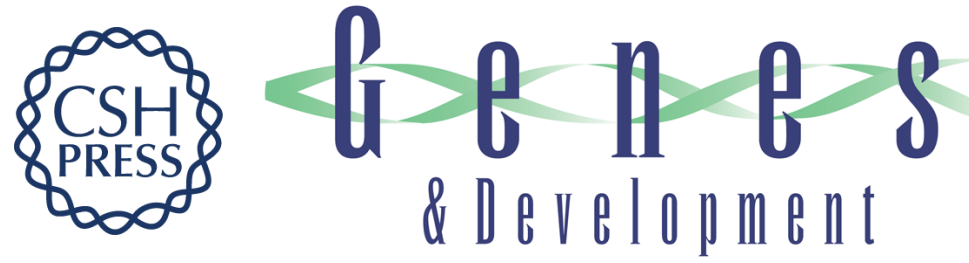

\section{Activation and repression of transcription by the gap proteins hunchback and Krüppel in cultured Drosophila cells.}

P Zuo, D Stanojevic, J Colgan, et al.

Genes Dev. 1991, 5:

Access the most recent version at doi:10.1101/gad.5.2.254

References This article cites 61 articles, 9 of which can be accessed free at:

http://genesdev.cshlp.org/content/5/2/254.full.html\#ref-list-1

License

Email Alerting

Service

Receive free email alerts when new articles cite this article - sign up in the box at the top right corner of the article or click here.

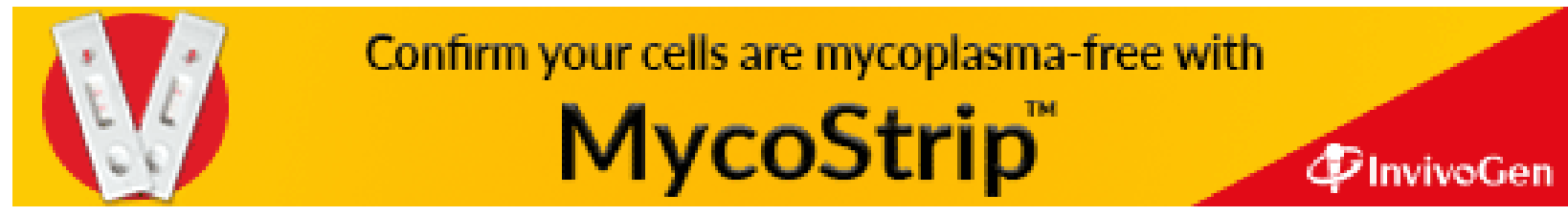

